\title{
Review Article \\ Recent Developments in Diagnosis and Care for Girls in Turner Syndrome
}

\author{
Carolyn Bondy \\ National Institute of Child Health and Human Development, National Institutes of Health, CRC 1-3330, 10 Center Dr, NIH, \\ Bethesda, MD 20892, USA \\ Correspondence should be addressed to Carolyn Bondy; bondycar@gmail.com
}

Received 8 May 2014; Accepted 9 September 2014; Published 16 November 2014

Academic Editor: Klaus Brusgaard

Copyright (C) 2014 Carolyn Bondy. This is an open access article distributed under the Creative Commons Attribution License, which permits unrestricted use, distribution, and reproduction in any medium, provided the original work is properly cited.

The past decade produced important advances in molecular genetic techniques potentially supplanting the traditional cytogenetic diagnosis of Turner syndrome (TS). Rapidly evolving genomic technology is used to screen 1st trimester pregnancies for sex chromosomal anomalies including TS, and genomic approaches are suggested for the postnatal diagnosis of TS. Understanding the interpretation and limitations of new molecular tests is essential for clinicians to provide effective counseling to parents or patients impacted by these tests. Recent studies have advanced the concept that X chromosome genomic imprinting influences expression of the Turner phenotype and contributes to gender differences in brain size and coronary disease. Progress in cardiovascular MRI over the past decade has dramatically changed our view of the scope and criticality of congenital heart disease in TS. Cardiac MRI is far more effective than transthoracic echocardiography in detecting aortic valve abnormalities, descending aortic aneurysm, and partial anomalous pulmonary venous return; recent technical advances allow adequate imaging in girls as young as seven without breath holding or sedation. Finally, important developments in the area of gynecological management of girls and young women with TS are reviewed, including prognostic factors that predict spontaneous puberty and potential fertility and recent practice guidelines aimed at reducing cardiovascular risk for oocyte donation pregnancies in TS.

\section{Introduction}

Clinical consensus defines Turner syndrome (TS) as a genetic disorder due to "complete or partial" X chromosome monosomy, with short stature the most constant feature, and variable expressivity of ovarian, cardiovascular, and renal defects [1]. The phrase "complete or partial" is used to include several chromosomal etiologies leading to the syndrome. The most common is pure X monosomy (45,X-formerly designated 45X0). Some authors do not believe that complete $\mathrm{X}$ monosomy is compatible with survival and postulate the existence of a normal cell line that rescues the embryo during early gestation [2]. This view suggests that most if not all surviving apparently $45, \mathrm{X}$ girls arose via loss of the 2 nd sex chromosome during early mitotic cell divisions in preimplantation embryos [2]. This hypothetical scenario seems unlikely for several reasons. Firstly, available research on human gametes and embryos indicates that aneuploidy and chromosomal fragmentation commonly occur during meiosis, related to errors of homologous recombination $[3,4]$. Moreover, if a sex chromosome is lost very early in embryo development, at least half of cells would retain a normal or trisomic sex chromosome complement, and it seems quite unlikely that the healthy cell line would die out while the abnormal 45,X cells take over during fetal development.

Early in the study of chromosomal disorders, it was thought that monosomy per se would prevent normal cell proliferation and differentiation [5]. However, in recent years, it has been shown that mice with pure $\mathrm{X}$ monosomy survive and develop normally [6] and that human 45,X cells proliferate and differentiate into various cell types in vitro $[7,8]$. Moreover, with progress in genotype-phenotype research in humans and mice, it has become very clear that penetrance and expressivity of specific gene deletions is highly dependent on the individual genetic "background" and environmental factors. Thus, it seems that X monosomy need not always be lethal, and the survival and relatively healthy development of some 45,X girls are more likely related to variation in 


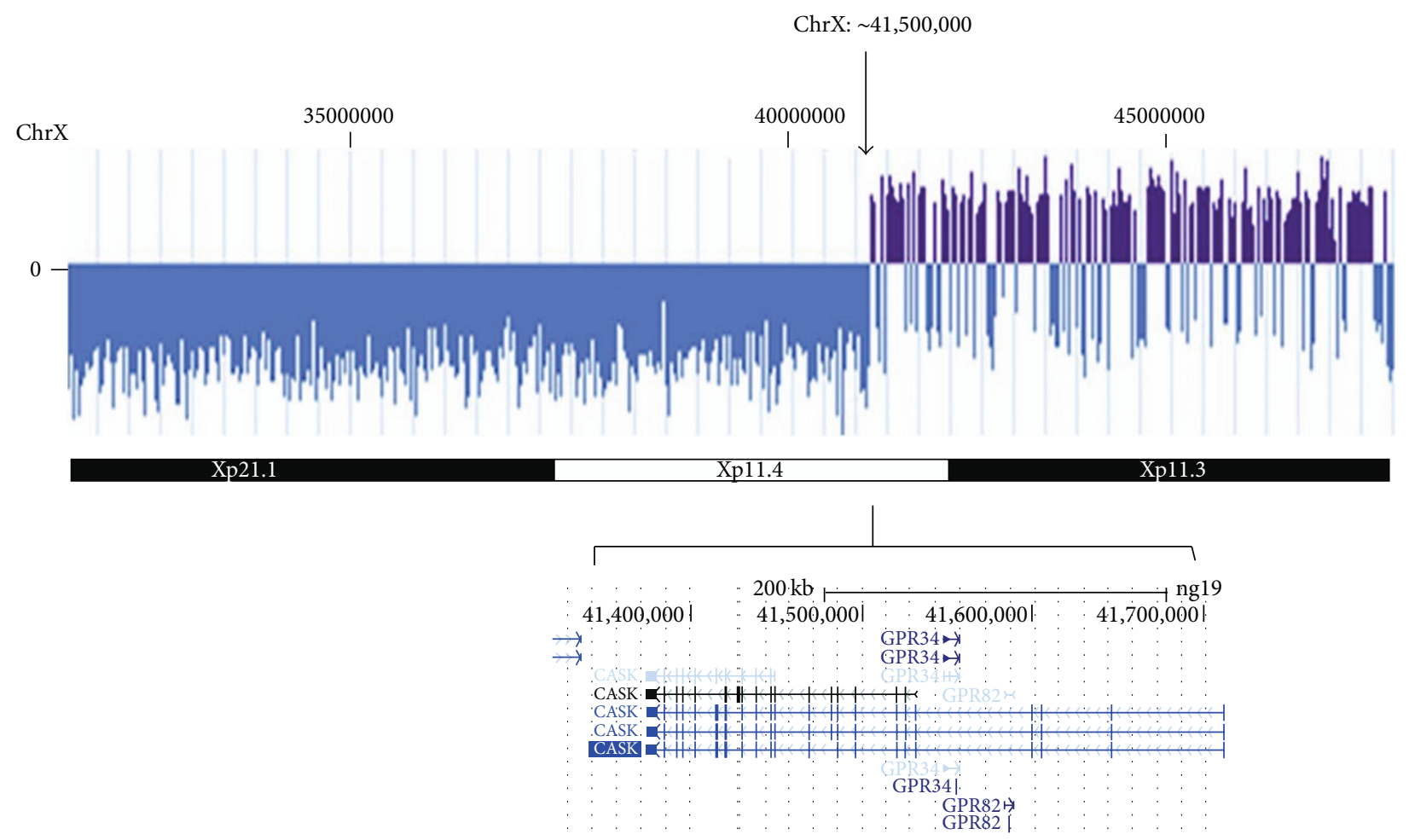

FIGURE 1: Xp deletion in a patient with BAV and aortic coarctation. The breakpoint is at X p11.4 and ChX 41,500,000 shown by array comparative genomic hybridization (aCGH). The break interrupts the gene CASK between the eighth and ninth exons. In this type of array analysis, genomic DNA from controls (reference sample) is labeled with one color dye, while gDNA from the test subject is labeled with a dye of a different color. The labeled test and reference samples are mixed together, denatured, and allowed to hybridize to the microarray which contains DNA probes. In this case we used high-resolution custom X chromosome tiling arrays containing 220,000 probes with average $280 \mathrm{bp}$ spacing (Agilent Technology). Only theX chromosome short arm (Xp) is illustrated here, with pter at the extreme left and centromere to the right. The presence of competitive hybridization from both reference and test samples is obvious up until ChX 41,500,000, where the test signal completely disappears, indicating the Xp deletion at that locus. The figure is adapted from [11].

autosomal genes and/or maternal effects that compensate for the sex chromosome haploinsufficiency, as opposed to cryptic rescue cell lines.

The term "partial X monosomy" includes two distinct chromosomal etiologies for TS. About $15 \%$ of patients in clinical series have mosaicism for 46,XX and/or 47,XXX cell lines in addition to 45,X cell line. This chromosomal constitution originates from sex chromosome loss during mitotic divisions occurring during early development. These girls typically have a milder Turner phenotype depending on the relative abundance of cells with two or more X chromosomes. The second type of "partial X monosomy" refers to fragmentation or rearrangement of the 2 nd sex chromosome involving deletion of the short arm. This class of chromosomal defect usually arises from errors in meiotic recombination. The abnormal fragmentary sex chromosome is frequently lost during mitotic cell divisions in the course of postzygotic development, resulting in mosaicism for the original cell with fragmentary sex chromosome and a pure monosomic cell line, for example, $46, \mathrm{X}$,isoXq/45,X. This type of mosaicism does not ameliorate the phenotype since all cells have monosomy for the $\mathrm{X}$ chromosome short arm (Xp).
The major phenotypic features of TS such as short stature, congenital cardiovascular defects, and neurocognitive differences are linked to deletion of $\mathrm{X}$ or $\mathrm{Y}$ chromosome short arms [9-11]. The short arm terminal regions of both $X$ and $Y$ chromosomes encode homologous genes that enable meiotic pairing and recombination between the sex chromosomes [12]. Pseudoautosomal genes are expressed from both $\mathrm{X}$ chromosomes in females and from the $\mathrm{X}$ and $\mathrm{Y}$ chromosomes in males. Haploinsufficiency for the pseudoautosomal gene termed SHOX is responsible for the short stature and skeletal anomalies characteristic of TS [13]. The genes related to cardiovascular and cognitive effects also map to the sex chromosome short arms $[10,11]$ but have not been identified. We recently showed that the locus for congenital heart defects in TS map telomeric to cytological band Xp11.4 and ChrX:41,500 000 [11]. This breakpoint was established by array-based comparative genomic hybridization (aCGH) as shown in Figure 1. This genomic technology represented a transition from classic cytogenetics through FISH to artificial chromosomes immobilized on arrays as shown here.

The diagnosis of TS requires not just evidence of abnormal sex chromosome complement, but also major clinical 
features, including short stature. Phenotypically normal adult women undergoing investigation of infertility may be found to have deletion of terminal portions of an Xq (long arm) without other features of TS and they should not be classified with TS.

\section{Increasing Challenges of Prenatal Diagnosis}

The interpretation of prenatal diagnoses of sex chromosome anomalies is one of the most common and difficult challenges encountered by practitioners responsible for advising the parents. This issue is only getting more challenging as new genomic testing strategies with unclear parameters of sensitivity, specificity, and clinical significance seem to emerge each year. The prognosis for girls with prenatally diagnosed TS detected by standard cytogenetic analyses of fetal tissue obtained by amniocentesis or chorion villous sampling is strongly related to the circumstances of the testing. When testing is prompted by an abnormal fetal ultrasound, the finding of a nonmosaic $45, \mathrm{X}$ fetal karyotype is strongly linked with a clinically significant diagnosis of TS, and a high risk of fetal demise [14]. In contrast, an incidental prenatal cytogenetic diagnosis of TS accompanied by a normal fetal ultrasound is often associated with a minimal postnatal phenotype [15]. Postnatal outcomes for fetuses mosaic for $45, \mathrm{X}$ and normal $46, \mathrm{XX}$ or $46, \mathrm{XY}$ cell lines do not correlate with phenotypes of children ascertained on clinical grounds [16]. Most mosaic 45,X/46,XY and 45X/46XX cases ascertained by amniocentesis or chorionic sampling done because of maternal age are born normally developed [15, 17, 18]. Moreover, in some cases, the postnatal karyotype may be normal, mandating caution in judging the results of prenatal cytogenetics.

Recent developments in genomic technology may soon replace traditional cytogenetic analysis for prenatal genetic diagnosis. A recent large, multicenter study of prenatal diagnosis testing compared chromosomal microarray analyses of fetal tissues versus standard karyotyping [19]. The study used both CGH arrays and the newer single nucleotide polymorphism (SNP) genotyping arrays. Both array types provide higher resolution detection of submicroscopic deletions or duplications (copy number variations, CNV) compared to classic cytogenetic analysis. Both array types confirmed the results obtained by standard karyotyping on nonmosaic samples derived from amniocentesis or CVS, including confirmation of nonmosaic 45, $\mathrm{X}$ in nineteen samples [19].

The use of high-resolution microarray analysis on fetal tissue samples raises many difficult questions for clinicians and counselors, since the clinical significance of many of the CNVs detected by arrays is quite uncertain. With specific regard to TS, the arrays seem to consistently detect $45, \mathrm{X}$ cases, but have not been tested on mosaic aneuploidies which represent $\sim 50 \%$ of TS gestations, so for now, a standard karyotype is still required for the prenatal diagnosis of TS.

Even more challenging prospects for prenatal genetic counseling lie ahead, as highly sensitive DNA sequencing strategies are developed to detect genetic abnormalities in small quantities of cell-free fetal DNA found in the maternal blood stream as early as 10 weeks gestation. The type of genetic testing is aimed primarily at detecting trisomies 21, 13, and 18, and Turner and Klinefelter syndromes. This type of testing has never been correlated with fetal/postnatal outcomes, and reproductive authorities currently advise that these early tests constitute "screening" that requires further investigation by amniocentesis or fetal ultrasound later in pregnancy. However, it seems clear that the widespread development and adoption of these new early screening tests are motivated by the desire to facilitate "early reproductive decision making." It is completely unknown at present whether the very early pregnancy genetic screening of "cellfree" fetal DNA shed from dead placental cells will have any correlation with more established diagnostic results available later in pregnancy or with postnatal outcomes. Thus, the current enthusiasm for this unproven technology to "facilitate early reproductive decision-making" is very concerning.

\section{New Genomic Tests for Postnatal Diagnosis of TS}

For the past several decades, a chromosomal karyotype has been the "gold standard" for the definitive diagnosis of Turner syndrome $[1,20]$. This test requires a fresh blood sample from which mononuclear cells are extracted and induced to proliferate for several days, after which a mitotic poison is added to arrest cells in metaphase to facilitate chromosomal identification under the light microscope. In some cases the standard karyotype reveals small fragments of chromosomal material known as marker or ring chromosomes that cannot be identified as derived from X or Y chromosomes based on morphology. These fragments require identification using fluorescent in situ hybridization (FISH) with $\mathrm{X}$ and $\mathrm{Y}$ chromosome specific probes.

Progress toward a new approach to genetic screening for TS among infants and young girls was pioneered by Rivkees et al. [21], using PCR and pyrosequencing for SNP genotyping of 18 alleles on the $\mathrm{X}$ chromosome and one on the $\mathrm{Y}$ chromosome. The conceptual basis for this approach is that individuals with a single $\mathrm{X}$ chromosome lack diversity for polymorphic $\mathrm{X}$ sequences. The method was designed to be faster, less costly, and applicable to fresh blood or buccal samples. The initial study was able to confirm cytogenetic diagnoses of about $95 \%$ of girls with TS [21]. Since this test is adapted for buccal swab analyses, the method could be used for noninvasive screening of newborns, although the diagnosis would have to be confirmed by standard karyotyping until considerably more data and clinical followup establish this methodology. The original study had a small sample size and did not address more complex karyotypes likely to challenge this method, for example, 45X/47XX or derivative $\mathrm{Y}$ chromosomes lacking the single polymorphic site used in their analysis.

Just a few years ago, array CGH was the first line test for genetic diagnosis of developmental disorders, congenital anomalies, and for investigation of chromosomal alterations in cancer-largely replacing the laborious and relatively low resolution, traditional karyotype. Now, the whole genome SNP genotyping array may surpass CGH 
arrays as diagnostic tool of choice, because the SNP arrays also provide information on loss of heterozygosity (as in monosomy $\mathrm{X}$, uniparental isodisomy or tumor genomes). Whole genome mapping SNP arrays are commercially available from Affymetrix, Agilent, Illumina, and other molecular technology companies. These arrays are widely available with cost to patient not very different from the standard 20-cell karyotype. We have compared results from Illumina and Affymetrix whole genome SNP arrays on a group of NIH TS patients that all had high resolution 50-cell karyotypes and found near perfect agreement between the two array types (our unpublished data) indicating that these high density arrays are essentially interchangeable. The Illumina OmniExpress chip used for our recent study [22] includes more than 18,000 SNPs covering the X chromosome and 1409 for the Y (compare to 18 and one, respectively, for the Rivkees test). This dense coverage allows high resolution mapping of $\mathrm{X}$ and $\mathrm{Y}$ chromosome deletions and provides novel haplotype information illuminating meiotic versus mitotic origins of $\mathrm{X}$ isochromosomes.

Figure 2 illustrates a SNP array analysis of an X chromosome from a TS subject showing monosomy for the short arm and trisomy for the long arm, that is, an isoX chromosome. The chromosome segmental copy number is plotted as the $\log R$ ratio, which shows single copy $\mathrm{Xp}$ sequences from a pericentromeric breakpoint to Xpter. The beta allele frequency indicates homozygosity of the Xp sequences, confirming Xp monosomy. The $\log R$ ratio increases dramatically from the site of the deletion through the entire length of X chromosome long arm (Xq), indicating three copies, consistent with an isoXq chromosome from Xp11. The beta allele frequency plotting for $\mathrm{Xq}$ confirms presence of two identical and one dissimilar long arm. This data is from one of the NIH subjects participating in the GenTAC [22] study who had a 50-cell karyotype confirming the array result.

While the extensive SNP array coverage of the whole genome may seem excessive in providing more information than needed to diagnose TS, they have the advantage of being widely available with well-established analytical protocols. The array analyses are performed on fresh blood or tissue samples and may soon be cost competitive with traditional cytogenetic karyotype analysis, given the large scale application of this technology. These arrays are able to demonstrate $\mathrm{X}$ monosomy, $\mathrm{X}$ chromosome deletions, and detect $\mathrm{Y}$ chromosome presence equivalent to conventional metaphase karyotypes [22]. Limitations of the whole genome arrays and Rivkees approach include

(i) inability to detect ring or marker chromosomes composed of repetitive noncoding $\mathrm{X}$ or $\mathrm{Y}$ chromosome sequences not represented by the SNPs,

(ii) inability to detect balanced translocations,

(iii) the possibility of not detect clinically significant TS in cases of $45, \mathrm{X} / 47, \mathrm{XXX}$ or $45 \mathrm{X} / 46 \mathrm{XX} / 47 \mathrm{XXX}$ mosaicism,

(iv) the possibility of not detecting low level $45 \mathrm{X}$ cell line.

\section{X Chromosome Genomic Imprinting}

The parental origin of the single $\mathrm{X}$ chromosome may influence expression of aspects of the Turner phenotype that typically demonstrate sexual dimorphism in the general population [23], for example, brain size, risk for autistic spectrum disorders, abdominal adiposity, and atherosclerosis. Skuse et al. initially reported selectively impaired social and verbal skills among Turner girls with a single maternal $\mathrm{X}$ chromosome versus those with a paternal $\mathrm{X}$, suggesting that imprinting of $\mathrm{X}$-linked genes contributes to sex-based differences in communication skills and risk for autism spectrum disorders [24]. Subsequent studies showed that certain $\mathrm{X}$ chromosome genes are subject to imprinting in murine brains $[25,26]$, consistent with a sex-steroidindependent role for $\mathrm{X}$ chromosomal genomic imprinting in brain development. A recent MRI study found that brain volumes are greatest in prepubertal Turner girls monosomic for a maternally-derived X chromosome (100\% brain cell $\mathrm{Xm}$ expression), intermediate in 46,XX girls (50\% brain $\mathrm{Xm}$ expression; 50\% Xp expression), and smallest in girls monosomic for a paternally-derived X chromosome $(0 \% \mathrm{Xm}$ and $100 \%$ Xp expression), consistent with a positive effect of maternal X chromosome dose on brain volume [27]. These observations may help explain the generally larger brain volumes in males, even after adjusting for differences in somatic size, since males are obligate carriers of a maternal $\mathrm{X}$.

We reported several years ago that young women with maternal X monosomy demonstrate male-pattern abdominal adiposity which is associated with an atherogenic lipid profile [28], which may contribute to greater risk for atherosclerosis among women with Turner syndrome and among the general male population. Over the subsequent years, we used coronary artery calcium scans to quantitate development of coronary atherosclerosis in these women as they aged. We have recently shown that women in their 40 s monosomic for a maternal X (XM) had significant early calcium accumulation, while women of the same age, matched for known coronary risk factors, who were monosomic for a paternal X chromosome, had undetectable coronary calcium (MANUSCRIPT UNDER REVIEW). Remarkably, recent studies have shown that the XM group had abundant coronary calcium deposits, similar to men of the same age, and control 46,XM,XP women had less calcium than men, but substantially more that the Turner XP group, suggesting either a proatherosclerosis effect of XM, or protective effect of XP (MANUSCRIPT UNDER REVIEW). In addition, we measured aortic compliance in the two groups and found that the XM group had significantly impaired compliance and greater stiffness of the arterial wall, consistent with atherosclerrotic vascular disease [29].

\section{Cardiovascular Screening}

Interestingly, aortic coarctation was a key feature in the original study linking the Turner phenotype to X monosomy [30]. Almost $10 \%$ of girls with TS present in infancy or childhood with severe cardiovascular symptoms caused by left heart hypoplasia, aortic stenosis, aortic coarctation, or 

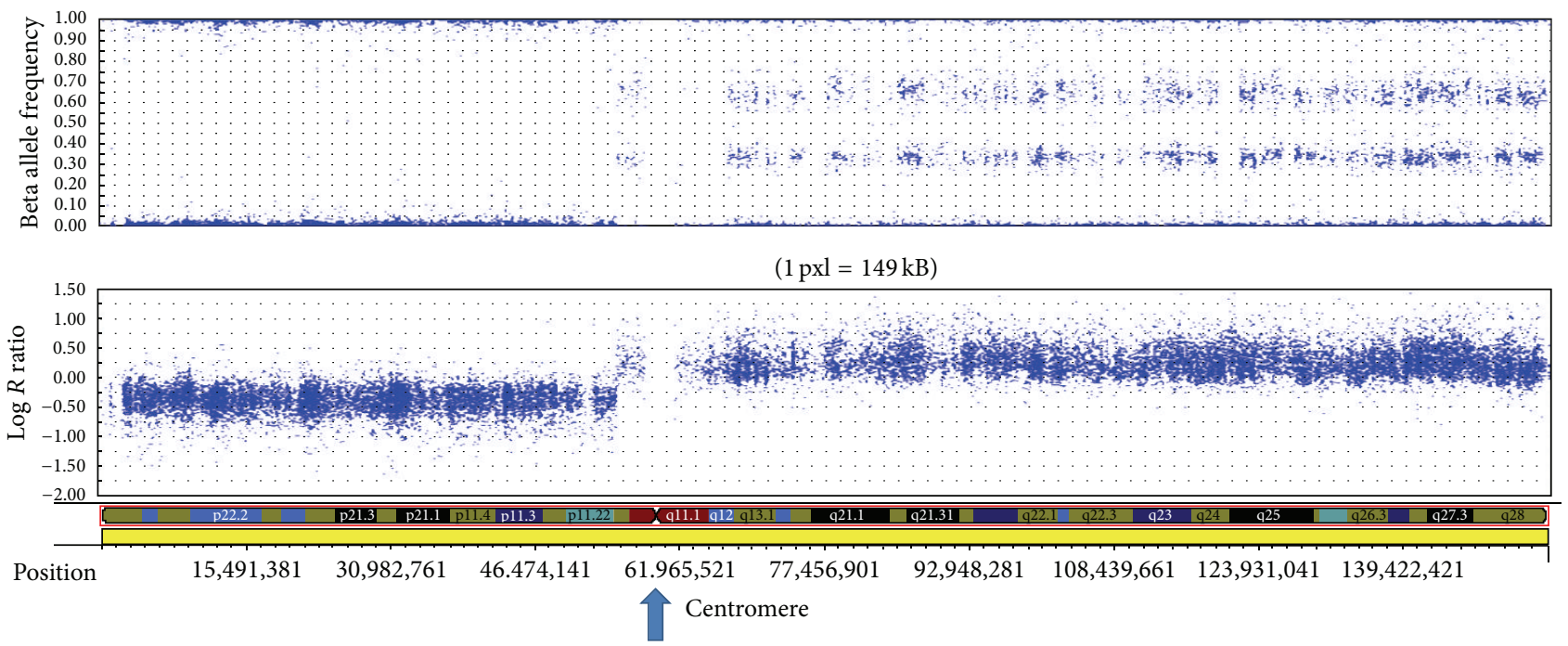

FIGURE 2: X chromosome single-nucleotide polymorphism (SNP) array from a patient with TS. Beta allele frequency is shown in the top panel. This analysis quantifies detection of polymorphic sites along the X chromosome. For example, homozygosity for a hypothetic SNP allele (AA) is reported as zero, heterozygosity (Aa) is reported as 0.5 , and homozygosity for the alternative allele (aa) is reported as 1 . When two parental chromosomes are present, the betal allele frequency averages 0.5 . Log $R$ ratios are shown on the lower panel. This measures copy number variation for the chromosome segments represented on the array. When test subject value is equal to the reference control ( $1: 1$ ratio), the $\log R$ (LRR) ratio is zero. Copy number loss shows a negative LRR, while copy number gain shows a positive LRR. The $\mathrm{X}$ chromosome physical structure is diagrammed below the graphs. In this example, there is loss of heterozygosity and negative $(\sim-.45)$ LRR beginning at Xp11.22 to Xpter, indicating segmental monosomy for the X chromosome short arm from Xpter-Xp11.22. The abrupt increase of LRR to 0.26 and division of BAF into four tracks $(1.00,0.66,0.34$, and 0$)$ indicate trisomy of Xp11-Xqter. The 50-cell standard karyotype revealed $46, \mathrm{X}, \mathrm{isoXp11.} \mathrm{This} \mathrm{figure} \mathrm{is} \mathrm{adapted} \mathrm{from} \mathrm{[22].}$

more complex outflow tract defects [31]. About 5\% of girls presenting with aortic coarctation are found to have TS when evaluated by karyotype analysis [32]. Thus, it seems appropriate that all girls presenting with one of these congenital defects should be tested for TS. Most girls with TS, however, are diagnosed due to short stature and/or delayed puberty at age 10-12 years, without clinical signs or symptoms of congenital heart disease.

Transthoracic echocardiography has been the standard approach to screening for and evaluation of congenital cardiovascular disease for decades, but this methodology has significant limitations in detecting cardiovascular anomalies in TS. For example, several large scale screening studies of girls with TS using echocardiography around the turn of the century reported prevalence of BAV of $\sim 14 \%$ [33-35]. More recent cardiac imaging studies using cardiovascular MRI (CMR), however, consistently find BAV prevalence greater than 30\% [36-38]. The most recent study examined 208 patients with karyotype proven TS with a specific focus on aortic valve anatomy, using both echocardiography and CMR [36]. These cardiac echoes were performed in an academic center with a dedicated research focus on cardiac anomalies and senior staff with extensive experience with TS [37]. Nevertheless, the cardiac echo was inaccurate or inadequate in almost $25 \%$ of study subjects [36]. Likewise, the prevalence of partial anomalous pulmonary venous return is estimated at $1-5 \%$ by the above referenced echo studies, while CMR reveals a prevalence of $16 \%[38,39]$.
One might ask why it is so important to detect asymptomatic cardiovascular anomalies in TS. One important reason is that the aortic valve malformation in TS is linked to aortopathy independent of the degree of valve malfunction, so even a very mild valve defect such as partial leaflet fusion is associated with aortic dilation and we fear risk for development of complications including aortic aneurysm or dissection. Unfortunately, there are many cases where the 1st clinical presentation of aortic valve disease in young women with TS was aortic dissection or aneurysm (see below). Thus, knowing that there is an abnormal valve alerts the clinician to enroll the girl in a life-long program of cardiological surveillance, to provide advice on potential risks of extreme sports and pregnancy [40] and educate the parents and older child on signs and symptoms of aortic dissection. Another important reason to have a very clear picture of the cardiac phenotype is to facilitate the identification of the gene(s) involved in the trait.

CMR studies in TS have revealed a series of aortic arch anomalies common in TS that appear to signify the presence of aortopathy and risk for dissection, regardless of aortic valve status. One very common anatomic finding is an apparent elongation of the transverse arch, associated with a kink in the lesser curvature at the site of ductus insertion near the origin of the left subclavian artery [39]. In some cases there is a typical coarctation shelf in the aorta at that site, and frequently a ballooning of the descending aorta or of the subclavian artery associated with this kink, despite no 


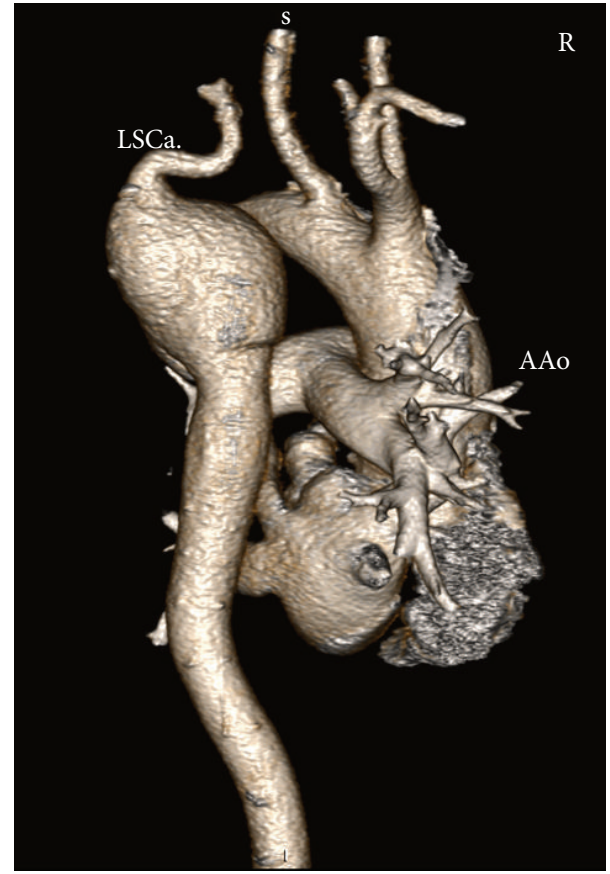

FIGURE 3: 3D reconstruction of cardiothoracic imaging in an asymptomatic young woman with TS. She had been "followed" with cardiac ultrasound in the years preceding admission to the NIH TS protocol. The cardiothoracic surgeons reviewed her imaging and recommended surgery on a semiurgent basis (she was considered a "walking time bomb"). She had a BAV, ascending aortic (Aao) aneurysm of $4.5 \mathrm{~cm}$ and descending aortic aneurysm of $6 \mathrm{~cm}$ involving the origin of the left subclavian artery (LSCa). Image courtesy of Marcus Chen, NHLBI.

evidence of actual stenosis or restriction of blood flow in the area. A significant number of aortic dissections in TS involve the descending aorta $[41,42]$, and we think they originate related to this anomaly.

A case illustrating these issues is presented in Figure 3. This image shows prominent aneurysms of the ascending and descending aorta both of which needed surgical correction. This young woman in her early 20 s had been diagnosed with TS at age 12; her initial screening cardiac echo was reported as “normal." Her cardiologist repeated echocardiography at 2-5 year intervals. During her teens the patient was told she had a mild coarctation that was hemodynamically insignificant and did not need treatment. However, screening CMR at the NIH showed aneurysms (4.5 maximum diameter for the ascending and $6 \mathrm{~cm}$ for the descending aorta) that were deemed critical putting her at risk for dissection or rupture. She underwent semiurgent surgical repair at the NIH. CMR also revealed a $B A V$ with moderate aortic regurgitation that was not detected by echocardiography. It seems quite likely that she had the characteristic deformity at the typical coarctation site that evolved over time into the huge aneurysm, apparently unrelated to flow restriction or hypertension.

The case study reenforces our recommendation that CMR be a first line screening tool for evaluation of newly diagnosed patients. This imaging provides excellent visualization of cardiovascular anatomy and function, with dimensions of ascending, transverse, and descending aorta easily and reproducibly measured in any desired imaging plane [43]. Technical advances in recent years allow the examination to take place relatively quickly, without need for breath-hold or sedation in girls as young as seven.

\section{Pubertal Development and Reproductive Options}

Although most individuals with TS have primary ovarian failure and resulting infertility, $15-30 \%$ will demonstrate spontaneous puberty [44] and $2-10 \%$ will have one or more natural pregnancies [44-47]. The question of potential fertility is of high importance to many girls with TS and their families and clinical investigators have pursued this issue over the past 10 years [48]. An important recent study employing ovarian biopsy has shown that a karyotype including 46,XX and/or 47,XXX cell lines is the most significant positive predictive factor for the presence of ovarian follicles, while karyotypes indicating nonmosaic 45,X or structural defects of one X chromosome were significant negative correlates for the presence of follicles [49]. Clinical factors such as normal FSH and AMH levels and spontaneous thelarche were also significant positive predictors of the presence of ovarian follicles and potential fertility, although less significant than karyotype [49]. It is essential to evaluate potential fertility in girls with TS to provide appropriate counseling, sex education, and use of contraception.

Spontaneous pregnancy is most common among Turner women with mosaicism for 46,XX (or 47,XXX) cell lines. However there are well documented reports of spontaneous pregnancies in apparently nonmosaic 45, X women with no evidence of mosaicism despite intensive investigation $[47,50,51]$. Additional evidence that some women retain ovarian function and fertility despite pure $\mathrm{X}$ monosomy is provided by three well-studied cases of sustained fertility in women whose second sex chromosome was a fragmentary $\mathrm{Y}$ chromosome [52-54], making the cryptic existence of 46 ,XX cell line extremely unlikely. Historical case series suggested a high frequency of fetal mortality or malformation in spontaneous pregnancies among women with Turner syndrome [55]. However, this has not been observed in more recent, population-based studies $[47,56]$ nor in women with $\mathrm{X}$ monosomy $[47,57]$. Additionally, a recent populationbased Swedish study investigating maternal age in nearly 500 births of girls with TS reports that age greater than 40 was a significant risk factor [58].

Since 1990, increasing numbers of women with TS have sought to become pregnant through assisted reproduction, using donor oocytes and in vitro fertilization. However, recent case series from the U.S. and France $[40,59]$ indicated a risk of approximately $2 \%$ for fatal aortic dissection during or immediately after oocyte donation pregnancies in women with TS. Based on these reports, professional societies from both nations issued practice guidelines designed to reduce this risk $[60,61]$. The guidelines emphasize the need to extensively and thoroughly screen prospective mothers, 
especially the cardiovascular system and exclude women with congenital defects such as BAV, coarctation, or aortic dilation. Importantly, the French have made it abundantly clear that conventional cardiac evaluation, in the "provinces" so to speak, relying upon routine echocardiography, is totally inadequate. Thus, evaluation by experts in adult congenital heart disease with use of modern imaging such as MRI or CT is essential to identify women at high risk. In addition, the guidelines mandate only single embryo transfer, followed by close surveillance by cardiology and high risk pregnancy specialists during the pregnancy. While special attention to medically assisted pregnancies is clearly mandated, spontaneous pregnancies in women with TS also need close medical surveillance, since fertility may occur in women with significant cardiovascular defects $[47,53]$, although only one case of (nonfatal) aortic dissection occurring in a natural pregnancy has been reported [53].

\section{Summary/Conclusions}

(i) Rapidly evolving advances in genomic technology provide vast quantities of data but little information on the data's clinical significance.

(ii) Widespread use of genetic testing on cell free fetal DNA in 1st trimester gestations poses major challenges to genetic counselors and clinicians involved in advising prospective parents since there is no information on their prognostic value for fetal outcomes.

(iii) Chromosome array tests applied to amniotic or chorionic fetal samples appear to provide genetic information comparable to traditional cytogenetic analysis.

(iv) Postnatal diagnosis of TS utilizing newer genetic screening tests requires further validation, with the 20-30 cell karyotype remaining the gold standard.

(v) Brain size is larger and coronary atherosclerosis is significantly advanced in groups of Turner subjects monosomic for a maternal X chromosome compared to those with a single paternal $\mathrm{X}$, implicating $\mathrm{X}$ chromosome genomic imprinting in these traits.

(vi) Cardiac magnetic resonance imaging is significantly superior to routine echocardiography for screening patients seven year and older.

(vii) Aneurysms and dissections occur at sites of minor anatomic anomalies without apparent hemodynamic compromise in young women with TS.

(viii) The likelihood of spontaneous puberty and potential fertility is predicted by a karyotype including 46XX and/or 47XXX cell lines and normal FSH and AMH levels.

(ix) Medically assisted pregnancies with donor oocytes should only be attempted in women free from underlying cardiovascular after comprehensive evaluation with CMR, transferring just one embryo, and accompanied by close medical follow-up during pregnancy.

\section{Future Directions}

It is of great importance to further investigate the clinical significance of apparent genetic anomalies detected by new prenatal screening tests.

Further studies are needed to establish whether new array-based genomic tests may adequately substitute for standard cytogenetic methods in diagnosis of sex chromosome disorders.

Longitudinal follow-up using CMR is needed to determine whether minor anatomic anomalies of the aortic valve and arch are associated with development of aortic aneurysms in TS and perhaps in other populations.

It is important to establish and monitor pregnancy registries to determine if, in fact, pregnancy may be safe in women without cardiovascular defects.

\section{Conflict of Interests}

The author declares that there is no conflict of interests regarding the publication of this paper.

\section{References}

[1] C. A. Bondy, "Clinical practice guideline: care of girls and women with Turner syndrome: a guideline of the Turner Syndrome Study Group," Journal of Clinical Endocrinology and Metabolism, vol. 92, no. 1, pp. 10-25, 2007.

[2] E. B. Hook and D. Warburton, "Turner syndrome revisited: review of new data supports the hypothesis that all viable 45, $\mathrm{X}$ cases are cryptic mosaics with a rescue cell line, implying an origin by mitotic loss," Human Genetics, vol. 133, no. 4, pp. 417424, 2014.

[3] P. A. Jacobs and T. J. Hassold, "The origin of numerical chromosome abnormalities," in Advances in Genetics, J. Hall, J. Dunlap, T. Friedmann et al., Eds., vol. 33, pp. 101-133, Academic Press, 1995.

[4] J. Lange, H. Skaletsky, S. K. M. van Daalen et al., "Isodicentric Y chromosomes and sex disorders as byproducts of homologous recombination that maintains palindromes," Cell, vol. 138, no. 5, pp. 855-869, 2009.

[5] T. Ogata and N. Matsuo, "Turner syndrome and female sex chromosome aberrations: deduction of the principal factors involved in the development of clinical features," Human Genetics, vol. 95, no. 6, pp. 607-629, 1995.

[6] F. J. Probst, M. L. Cooper, S. W. Cheung, and M. J. Justice, "Genotype, phenotype, and karyotype correlation in the XO mouse model of turner syndrome," Journal of Heredity, vol. 99, no. 5, pp. 512-517, 2008.

[7] W. Li, X. Wang, W. Fan et al., "Modeling abnormal early development with induced pluripotent stem cells from aneuploid syndromes," Human Molecular Genetics, vol. 21, no. 1, pp. 3245, 2012.

[8] A. Urbach and N. Benvenisty, "Studying early lethality of 45,XO (Turner's syndrome) embryos using human embryonic stem cells," PLoS ONE, vol. 4, no. 1, Article ID e4175, 2009.

[9] R. J. Blaschke and G. A. Rappold, "SHOX: growth, leri-weill and turner syndromes," Trends in Endocrinology \& Metabolism, vol. 11, no. 6, pp. 227-230, 2000. 
[10] A. R. Zinn, D. Roeltgen, G. Stefanatos et al., "A turner syndrome neurocognitive phenotype maps to Xp22.3," Behavioral and Brain Functions, vol. 3, article 24, 2007.

[11] C. Bondy, V. K. Bakalov, C. Cheng, L. Olivieri, D. R. Rosing, and A. E. Arai, "Bicuspid aortic valve and aortic coarctation are linked to deletion of the $\mathrm{X}$ chromosome short arm in turner syndrome," Journal of Medical Genetics, vol. 50, no. 10, pp. 662665, 2013.

[12] G. A. Rappold, "The pseudoautosomal regions of the human sex chromosomes," Human Genetics, vol. 92, no. 4, pp. 315-324, 1993.

[13] G. A. Rappold, M. Fukami, B. Niesler et al., "Deletions of the homeobox gene SHOX (short stature homeobox) are an important cause of growth failure in children with short stature," Journal of Clinical Endocrinology and Metabolism, vol. 87, no. 3, pp. 1402-1406, 2002.

[14] R. Ganapathy, M. Guven, F. Sethna, U. Vivekananda, and B. Thilaganathan, "Natural history and outcome of prenatally diagnosed cystic hygroma," Prenatal Diagnosis, vol. 24, no. 12, pp. 965-968, 2004.

[15] D. F. Gunther, E. Eugster, A. J. Zagar, C. G. Bryant, M. L. Davenport, and C. A. Quigley, "Ascertainment bias in turner syndrome: new insights from girls who were diagnosed incidentally in prenatal life," Pediatrics, vol. 114, no. 3, pp. 640-644, 2004.

[16] L. Telvi, A. Lebbar, O. Del Pino, J. P. Barbet, and J. L. Chaussain, “45,X/46,XY mosaicism: report of 27 cases," Pediatrics, vol. 104, no. 2, pp. 304-308, 1999.

[17] L. Y. F. Hsu, "Phenotype/karyotype correlations of Y chromosome aneuploidy with emphasis on structural aberrations in postnatally diagnosed cases," American Journal of Medical Genetics, vol. 53, no. 2, pp. 108-140, 1994.

[18] D. D. Koeberl, B. McGillivray, and V. P. Sybert, "Prenatal diagnosis of 45,X/46,XX mosaicism and 45,X: implications for postnatal outcome," The American Journal of Human Genetics, vol. 57, no. 3, pp. 661-666, 1995.

[19] R. J. Wapner, C. L. Martin, B. Levy et al., "Chromosomal microarray versus karyotyping for prenatal diagnosis," The New England Journal of Medicine, vol. 367, no. 23, pp. 2175-2184, 2012.

[20] P. Saenger, K. A. Wikland, G. S. Conway et al., "Recommendations for the diagnosis and management of Turner syndrome," Journal of Clinical Endocrinology and Metabolism, vol. 86, no. 7, pp. 3061-3069, 2001.

[21] S. A. Rivkees, K. Hager, S. Hosono et al., "A highly sensitive, high-throughput assay for the detection of Turner syndrome," The Journal of Clinical Endocrinology and Metabolism, vol. 96, no. 3, pp. 699-705, 2011.

[22] S. Prakash, D. Guo, C. L. Maslen et al., "Single-nucleotide polymorphism array genotyping is equivalent to metaphase cytogenetics for diagnosis of Turner syndrome," Genetics in Medicine, vol. 16, no. 1, pp. 53-59, 2014.

[23] C. A. Bondy, H. Y. Hougen, J. Zhou, and C. M. Cheng, "Genomic imprinting and Turner syndrome," Pediatric Endocrinology Reviews, vol. 9, supplement 2, pp. 728-732, 2012.

[24] D. H. Skuse, R. S. James, D. V. M. Bishop et al., "Evidence from Turner's syndrome of an imprinted X-linked locus affecting cognitive function," Nature, vol. 387, no. 6634, pp. 705-708, 1997.

[25] W. Davies, A. Isles, R. Smith et al., "Xlr3b is a new imprinted candidate for X-linked parent-of-origin effects on cognitive function in mice," Nature Genetics, vol. 37, no. 6, pp. 625-629, 2005.
[26] A. S. Raefski and M. J. O’Neill, “Identification of a cluster of Xlinked imprinted genes in mice," Nature Genetics, vol. 37, no. 6, pp. 620-624, 2005.

[27] J.-F. Lepage, D. S. Hong, P. K. Mazaika et al., "Genomic imprinting effects of the X chromosome on brain morphology," The Journal of Neuroscience, vol. 33, no. 19, pp. 8567-8574, 2013.

[28] P. L. Van, V. K. Bakalov, A. R. Zinn, and C. A. Bondy, "Maternal X chromosome, visceral adiposity, and lipid profile," Journal of the American Medical Association, vol. 295, no. 12, pp. 1373-1374, 2006.

[29] K. Z. Abd-Elmoniem, V. K. Bakalov, J. R. Matta et al., "X chromosome parental origin and aortic stiffness in Turner syndrome," Clinical Endocrinology, vol. 81, no. 3, pp. 467-470, 2014.

[30] P. Polani, W. F. Hunter, and B. Lennox, "Chromosomal sex in Turner's syndrome with coarctation of the aorta," The Lancet, vol. 264, no. 6829, pp. 120-121, 1954.

[31] V. P. Sybert, "Cardiovascular malformations and complications in Turner syndrome," Pediatrics, vol. 101, no. 1, article E11, 1998.

[32] S. C. Wong, T. Burgess, M. Cheung, and M. Zacharin, "The prevalence of turner syndrome in girls presenting with coarctation of the aorta," The Journal of Pediatrics, vol. 164, no. 2, pp. 259-263, 2014.

[33] C.-O. Gotzsche, B. Krag-Olsen, J. Nielsen, K. E. Sorensen, and B. O. Kristensen, "Prevalence of cardiovascular malformations and association with karyotypes in Turner's syndrome," Archives of Disease in Childhood, vol. 71, no. 5, pp. 433-436, 1994.

[34] L. Mazzanti and E. Cacciari, "Congenital heart disease in patients with Turner's syndrome. Italian Study Group for Turner Syndrome (ISGTS)," Journal of Pediatric, vol. 133, no. 5, pp. 688692, 1998.

[35] T. M. K. Völkl, K. Degenhardt, A. Koch, D. Simm, H. G. Dörr, and H. Singer, "Cardiovascular anomalies in children and young adults with Ullrich-Turner syndrome-the Erlangen experience," Clinical Cardiology, vol. 28, no. 2, pp. 88-92, 2005.

[36] L. J. Olivieri, R. Y. Baba, A. E. Arai et al., "Spectrum of aortic valve abnormalities associated with aortic dilation across age groups in turner syndrome," Circulation: Cardiovascular Imaging, vol. 6, no. 6, pp. 1018-1023, 2013.

[37] V. Sachdev, L. A. Matura, S. Sidenko et al., "Aortic valve disease in Turner syndrome," Journal of the American College of Cardiology, vol. 51, no. 19, pp. 1904-1909, 2008.

[38] H. K. Kim, W. Gottliebson, K. Hor et al., "Cardiovascular anomalies in turner syndrome: spectrum, prevalence, and cardiac MRI findings in a pediatric and young adult population," American Journal of Roentgenology, vol. 196, no. 2, pp. 454-460, 2011.

[39] V. B. Ho, V. K. Bakalov, M. Cooley et al., "Major vascular anomalies in Turner syndrome: prevalence and magnetic resonance angiographic features," Circulation, vol. 110, no. 12, pp. 16941700, 2004.

[40] N. Chevalier, H. Letur, D. Lelannou et al., "Materno-fetal cardiovascular complications in turner syndrome after oocyte donation: insufficient prepregnancy screening and pregnancy follow-up are associated with poor outcome," The Journal of Clinical Endocrinology \& Metabolism, vol. 96, no. 2, pp. E260E267, 2011.

[41] M. Carlson, N. Airhart, L. Lopez, and M. Silberbach, "Moderate aortic enlargement and bicuspid aortic valve are associated with aortic dissection in turner syndrome: report of the international turner syndrome aortic dissection registry," Circulation, vol.126, no. 18, pp. 2220-2226, 2012. 
[42] C. H. Gravholt, K. Landin-Wilhelmsen, K. Stochholm et al., "Clinical and epidemiological description of aortic dissection in Turner's syndrome," Cardiology in the Young, vol. 16, no. 5, pp. 430-436, 2006.

[43] K. H. Mortensen, B. E. Hjerrild, K. Stochholm et al., "Dilation of the ascending aorta in Turner syndrome-a prospective cardiovascular magnetic resonance study," Journal of Cardiovascular Magnetic Resonance, vol. 13, no. 1, article 24, 2011.

[44] A. M. Pasquino, F. Passeri, I. Pucarelli, M. Segni, and G. Municchi, "Spontaneous pubertal development in turner's syndrome," Journal of Clinical Endocrinology and Metabolism, vol. 82, no. 6, pp. 1810-1813, 1997.

[45] T. N. Hadnott and C. A. Bondy, "Risks of pregnancy for women with Turner syndrome," Expert Review of Obstetrics \& Gynecology, vol. 6, no. 2, pp. 217-227, 2011.

[46] O. Hovatta, "Pregnancies in women with Turner's syndrome," Annals of Medicine, vol. 31, no. 2, pp. 106-110, 1999.

[47] T. N. Hadnott, H. N. Gould, A. M. Gharib, and C. A. Bondy, "Outcomes of spontaneous and assisted pregnancies in Turner syndrome: the U.S. National Institutes of Health experience," Fertility and Sterility, vol. 95, no. 7, pp. 2251-2256, 2011.

[48] J. G. Hreinsson, M. Otala, M. Fridström et al., "Follicles are found in the ovaries of adolescent girls with Turner's syndrome," Journal of Clinical Endocrinology and Metabolism, vol. 87, no. 8, pp. 3618-3623, 2002.

[49] B. Borgström, J. Hreinsson, C. Rasmussen et al., "Fertility preservation in girls with turner syndrome: prognostic signs of the presence of ovarian follicles," Journal of Clinical Endocrinology and Metabolism, vol. 94, no. 1, pp. 74-80, 2009.

[50] M. Cools, R. P. A. Rooman, J. Wauters, Y. Jacqemyn, and M. V. L. Du Caju, "A nonmosaic 45,X karyotype in a mother with Turner's syndrome and in her daughter," Fertility and Sterility, vol. 82, no. 4, pp. 923-925, 2004.

[51] K. H. Mortensen, M. D. Rohde, N. Uldbjerg, and C. H. Gravholt, "Repeated spontaneous pregnancies in 45,X turner syndrome," Obstetrics and Gynecology, vol. 115, no. 2, pp. 446-449, 2010.

[52] F. Wei, S. Cheng, N. Badie et al., "A man who inherited his SRY gene and Leri-Weill dyschondrosteosis from his mother and neurofibromatosis type 1 from his father," American Journal of Medical Genetics, vol. 102, no. 4, pp. 353-358, 2001.

[53] K. Landin-Wilhelmsen, I. Bryman, C. Hanson, and L. Hanson, "Short communication: spontaneous pregnancies in a turner syndrome woman with Y-chromosome mosaicism," Journal of Assisted Reproduction and Genetics, vol. 21, no. 6, pp. 229-230, 2004.

[54] M.-F. Portnoï, S. Chantot-Bastaraud, S. Christin-Maitre et al., "Familial Turner syndrome with an $\mathrm{X} ; \mathrm{Y}$ translocation mosaicism: implications for genetic counseling," European Journal of Medical Genetics, vol. 55, no. 11, pp. 635-640, 2012.

[55] L. Tarani, S. Lampariello, G. Raguso et al., "Pregnancy in patients with Turner's syndrome: six new cases and review of literature," Gynecological Endocrinology, vol. 12, no. 2, pp. 83-87, 1998.

[56] A. Hagman, K. Källén, M.-L. Barrenäs et al., "Obstetric outcomes in women with turner karyotype," Journal of Clinical Endocrinology \& Metabolism, vol. 96, no. 11, pp. 3475-3482, 2011.

[57] K. H. Mortensen, L. Cleemann, B. E. Hjerrild et al., "Increased prevalence of autoimmunity in Turner syndrome-influence of age," Clinical and Experimental Immunology, vol. 156, no. 2, pp. 205-210, 2009.
[58] A. Hagman, U.-B. Wennerholm, K. Källén et al., "Women who gave birth to girls with Turner syndrome: maternal and neonatal characteristics," Human Reproduction, vol. 25, no. 6, pp. 1553$1560,2010$.

[59] M. F. Karnis, A. E. Zimon, S. I. Lalwani, L. S. Timmreck, S. Klipstein, and R. H. Reindollar, "Risk of death in pregnancy achieved through oocyte donation in patients with Turner syndrome: a national survey," Fertility and Sterility, vol. 80, no. 3, pp. 498-501, 2003.

[60] L. Cabanes, C. Chalas, S. Christin-Maitre et al., “ Turner syndrome and pregnancy: clinical practice. Recommendations for the management of patients with Turner syndrome before and during pregnancy," European Journal of Obstetrics Gynecology and Reproductive Biology, vol. 152, no. 1, pp. 18-24, 2010.

[61] Practice Committee of American Society for Reproductive Medicine, "Increased maternal cardiovascular mortality associated with pregnancy in women with Turner syndrome," Fertility and Sterility, vol. 97, no. 2, pp. 282-284, 2012. 


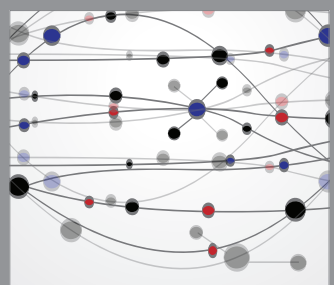

The Scientific World Journal
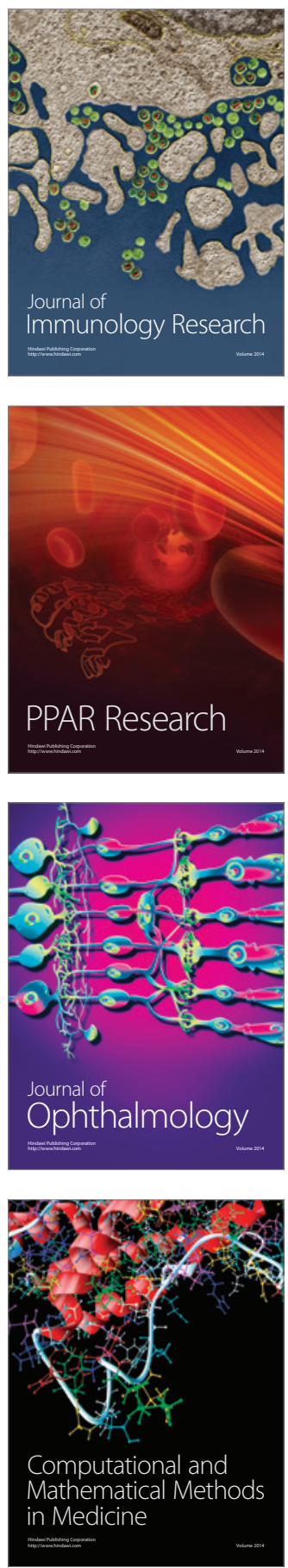

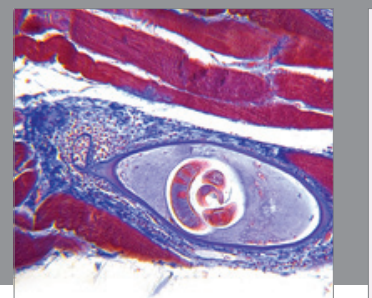

Gastroenterology

Research and Practice
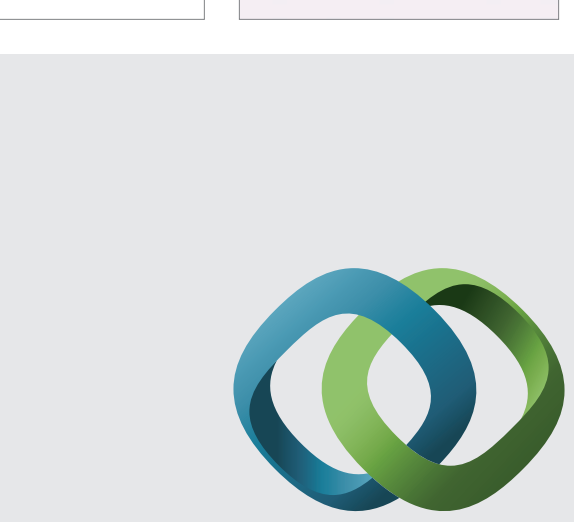

\section{Hindawi}

Submit your manuscripts at

http://www.hindawi.com
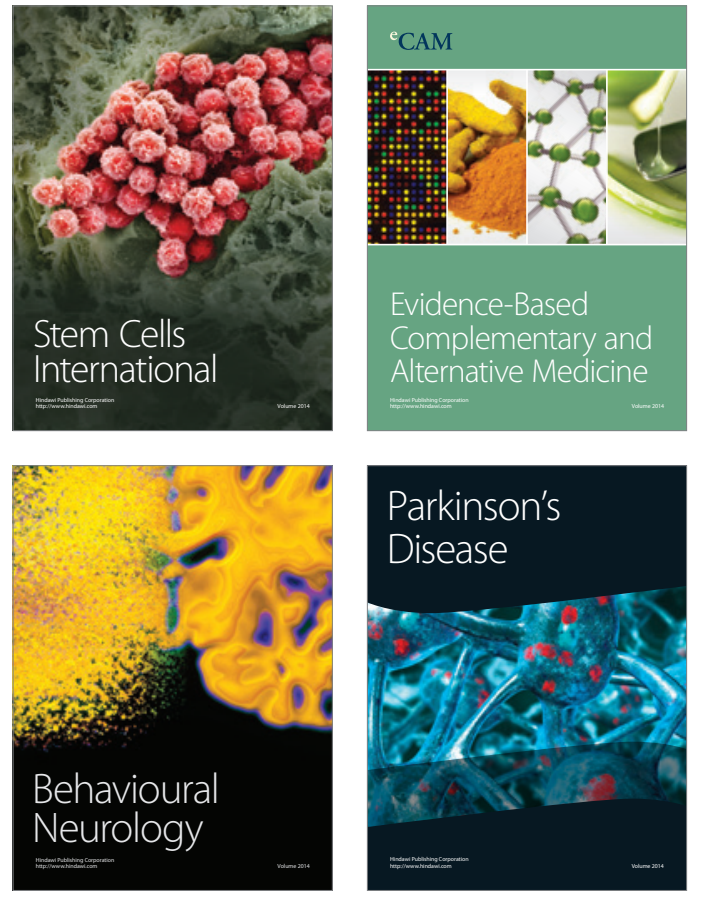
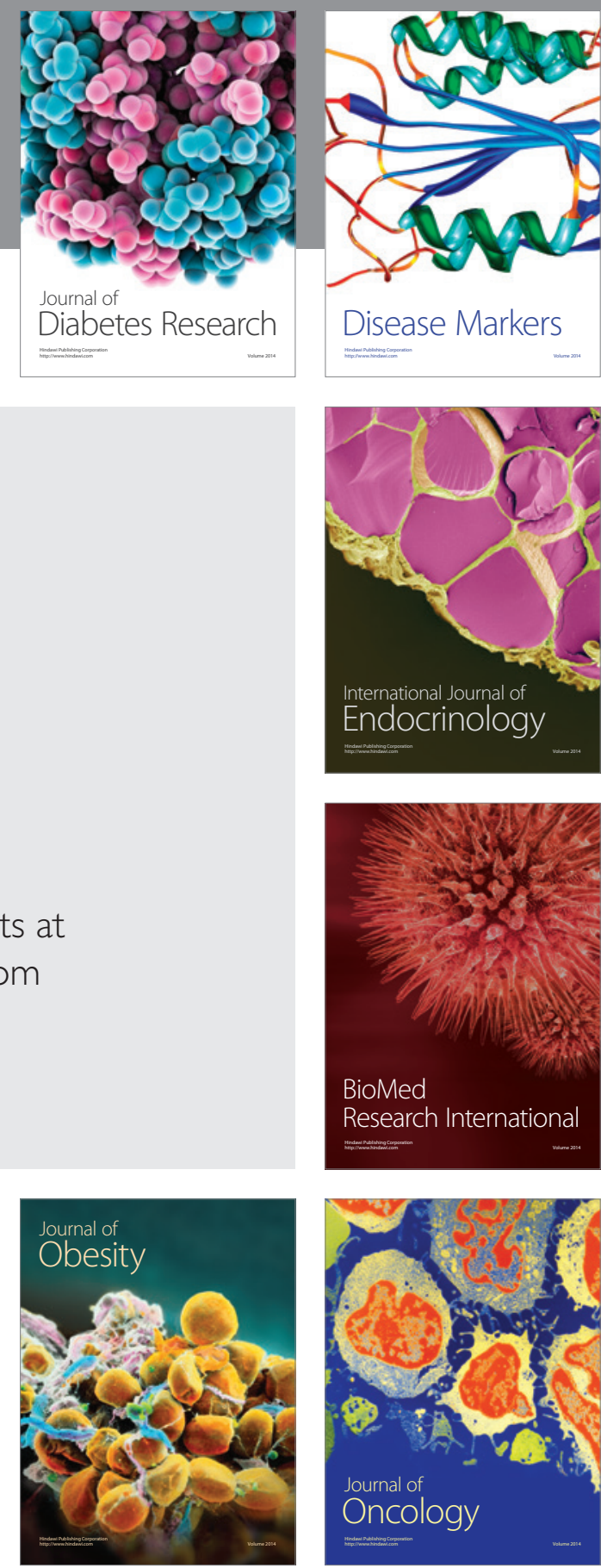

Disease Markers
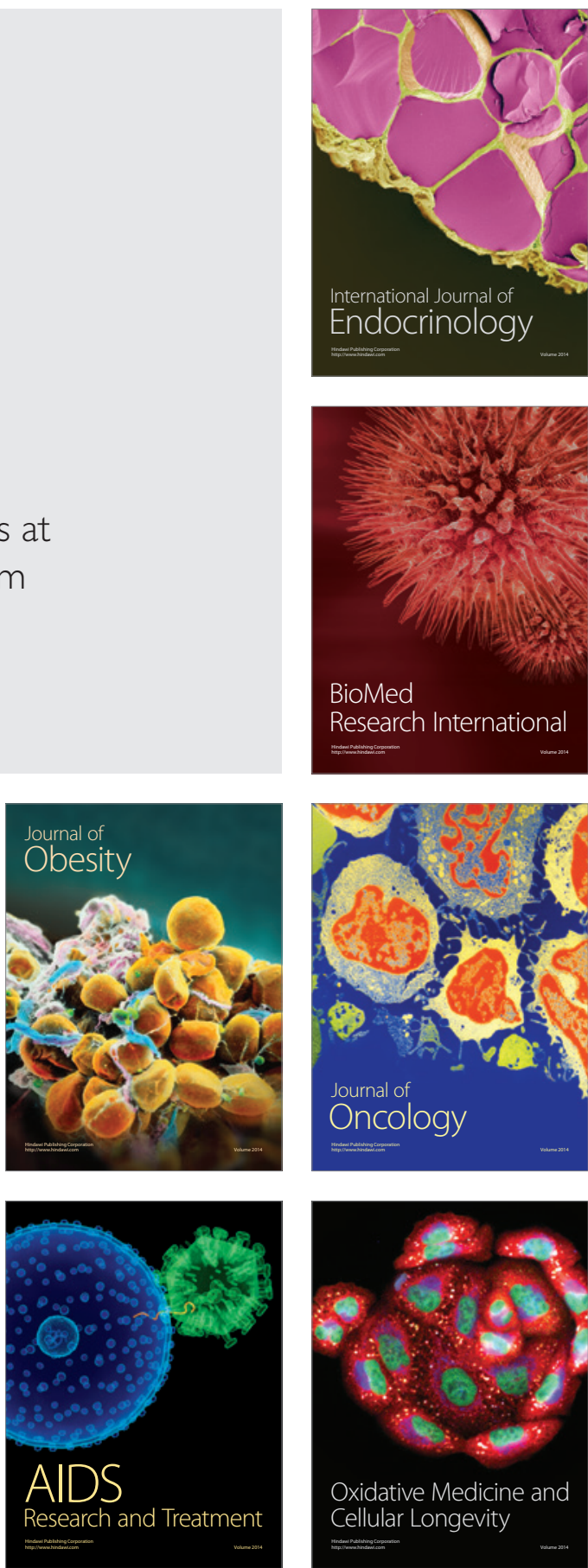